\title{
Puberdade precoce: fatores que influenciam sua ocorrência
}

\author{
Precocious puberty: factors that influence its occurrence \\ Pubertad precoz: factores que influyen en su aparición
}

Maria Eduarda Reis Correa ${ }^{1 *}$, Amanda Longo Louzada², Layra Ton ${ }^{3}$, Leonardo José Grossi Andrade $^{3}$, Lilian Rhodes Neves ${ }^{4}$, Maria Cecília Alcure Dias Scussulim ${ }^{4}$, Thaís de Oliveira Martins ${ }^{4}$, Mônica Isaura Corrêa ${ }^{4}$.

\section{RESUMO}

Objetivo: Revisar a literatura acerca da Puberdade Precoce (PP) e das suas principais causas. Revisão bibliográfica: A puberdade ocorre devido a alterações dos níveis hormonais, que desencadeiam a maturação sexual e o estirão de crescimento. A partir disso, foram analisados neste trabalho a definição, classificação, marcos principais e causas da puberdade precoce. Para identificação da PP, têm-se as faixas etárias da puberdade fisiológica feminina e masculina, juntamente com os marcos da puberdade, mediante a escala dos estágios de desenvolvimento. Buscou-se também classificar a puberdade precoce em central e periférica, diferenciando-as e expondo suas principais características. Ademais, foram descritas suas principais causas, analisando a fisiopatologia e seus principais aspectos. Em relação a PP central, as principais causas descritas foram as genéticas idiopáticas, neurológicas, funcionais, más formações, tumorais e císticas. Dentre as causas da PP periférica, destacam-se as tumorais, que são relacionadas ao hipotireoidismo, e as hiperplásicas. Considerações finais: Entende-se que é fundamental a classificação da PP para a escolha do melhor tratamento e, dessa forma, proporcionar o melhor prognóstico ao paciente.

Palavras-chave: Desenvolvimento sexual, Hormônios esteroides gonadais, Puberdade precoce.

\begin{abstract}
Objective: Review the literature on Precocious Puberty (PP) and its main causes. Bibliographic review: Puberty occurs due to changes in hormone levels, which trigger sexual maturation and growth spurt. From this, the definition, classification, main landmarks and causes of precocious puberty were analyzed in this work. To identify PP, the age groups of female and male physiological puberty are considered, together with the puberty milestones, through the scale of the stages of development. We also sought to classify precocious puberty into central and peripheral, differentiating them and exposing their main characteristics. Furthermore, its main causes were described, analyzing the pathophysiology and its main aspects. Regarding central PP, the main causes described were idiopathics genetics, neurologicals, functionals, malformations, tumoral and cystics. Among the causes of peripheral PP, tumors, which are related to hypothyroidism, and hyperplastic ones stand out. Final considerations: It is understood that the classification of PP is essential for choosing the best treatment and, thus, providing the best prognosis for the patient.
\end{abstract}

Key words: Sexual development, Gonadal steroid hormones, Puberty precocious.

${ }^{1}$ Centro Universitário de Belo Horizonte (UniBH), Belo Horizonte - MG. *E-mail: dudareisc@hotmail.com

2 Multivix (Multivix), Cachoeiro do Itapemirim - ES.

${ }^{3}$ Centro Universitário de Caratinga (UNEC), Caratinga - MG.

${ }^{4}$ Instituto Metropolitano de Ensino Superior (IMES), Ipatinga - MG.

SUBMETIDO EM: 8/2021

ACEITO EM: 9/2021

PUBLICADO EM: 9/2021 


\section{RESUMEN}

Objetivo: Revisar la literatura sobre la Pubertad Precoz (PP) y sus principales causas. Revisión bibliográfica: La pubertad se produce debido a cambios en los niveles hormonales, que desencadenan la madurez sexual y el crecimiento acelerado. A partir de ello, en este trabajo se analizó la definición, clasificación, principales hitos y causas de la pubertad precoz. Para identificar la PP se consideran los grupos de edad de pubertad fisiológica femenina y masculina, junto con los hitos de la pubertad, a través de la escala de las etapas de desarrollo. También buscamos clasificar la pubertad precoz en central y periférica, diferenciándo las y exponiendo sus principales características. Además, se describieron las principales causas, analizando la fisiopatología y sus principales aspectos. Encuanto a la PP central, las principales causas descritas fueron las genéticas idiopáticas, neurológicas, funcionales, malformaciones, tumorales y quísticas. Entre las causas de la PP periférica destacan las tumorales, que se relacionan con el hipotiroidismo, y las hiperplásicas. Consideraciones finales: Se entiende que la clasificación de la PP es fundamental para elegirel tratamento adecuadoy, así, proporcionar el mejor prognóstico para el paciente.

Palabras clave: Desarrollo sexual, Hormones esteroides gonadales, Pubertad precoz.

\section{INTRODUÇÃO}

A puberdade é o processo de amplas transformações físicas, psicológicas e biológicas que fazem parte do processo de maturação da fisiologia do organismo. Os mecanismos que controlam esse período envolvem fatores genéticos, fatores nutricionais e a interação ambiental (MEDEIROS PCS, et al., 2021). Esse evento caracteriza-se pelas mudanças que se manifestam na adolescência, sendo no sexo feminino entre os 8 e 13 anos de idade e no masculino entre 9 e 14 anos, e representam para o ser humano, o início da capacidade reprodutiva (GOMES RS, et al., 2019).

O marco da puberdade é refletido pelo aparecimento de botões mamários em meninas e alterações genitais em meninos, comandados pela reativação da secreção pulsátil do Hormônio Liberador das Gonadotrofinas $(\mathrm{GnRH})$, com consequente efeito no eixo Hipotálamo-Hipófise-Gonadal (HHG). Têm-se também as mudanças psicossociais, que resultam da estruturação identitária da criança, bem como sua orientação social fora do convívio familiar (MEDEIROS PCS, et al., 2021).

A Puberdade Precoce (PP) é o aparecimento das características sexuais secundárias antes dos oito anos de idade na menina e antes dos nove anos de idade no menino, enfatizando a passagem da infância para a vida adulta antes do devido tempo. É classificada como Puberdade Precoce Central (PPC), quando as características sexuais se desenvolvem por ativação precoce do eixo HHG, ou Puberdade Precoce Periférica (PPP), quando a secreção de esteróides sexuais ocorre independente da secreção das gonadotrofinas (GOMES RS, et al., 2019).

Para tanto, considerando a gravidade e as consequências na vida da criança acometida, define-se como objetivo do presente trabalho fazer uma revisão narrativa acerca dos fatores causais da PP.

\section{REVISÃO BIBLIOGRÁFICA}

O início da puberdade é indicado pela reativação do hormônio liberador de gonadotrofina decorrente do circuito neuronal hipotalâmico, que é secretado de forma rítmica e pulsátil após sua quiescência desde a infância, estimulando a glândula pituitária anterior a liberar os Hormônios Folículo Estimulante (FSH) e Luteinizante (LH). Juntos, o FSH e o LH iniciam a espermatogênese e a liberação de testosterona nos meninos, e a oogênese e a liberação de estradiol nas meninas (CARVALHO IV, 2018). Nesse momento ocorre a maturação sexual com aparecimento dos caracteres sexuais secundários, o avanço do crescimento e da maturação óssea, o desenvolvimento da capacidade fértil-reprodutiva e as alterações psicológicas decorrentes das pressões familiar, social e cultural (LIMA LPV, et al., 2018; MADEIRA IR e CORDEIRO MDM, 2019). 
Dessa maneira, é compreendida como puberdade precoce aquela que ocorre antes dos 8 anos nas meninas e dos 9 anos nos meninos. Esta pode ser classificada como PPC, PPP ou a forma mista. A puberdade precoce é causada pela exposição a algum hormônio, como em uso de medicamentos, ou por alterações glandulares (pituitária, ovários ou testículos), ocasionando o aumento dos hormônios sexuais no sangue precocemente. Ela tende a surgir precocemente em crianças em que as mães tiveram a menarca antecipada, com baixo peso ao nascer ou que são obesas (MADEIRA IR e CORDEIRO MDM, 2019; PAULA LCC e PUÑALES M, 2016).

As alterações físicas presentes na puberdade são decorrentes da maturação sexual e do estirão de crescimento, ambos desencadeados por alterações nos níveis hormonais. Essas mudanças no corpo da criança rumo à adolescência são determinadas, principalmente, por condições genéticas. As transformações que constituem a maturação sexual são mais precoces no sexo feminino, sendo a primeira delas o aparecimento do broto mamário, seguido da menarca. No sexo masculino, o primeiro marco do desenvolvimento é o aumento dos testículos, seguido pelo surgimento de pelos pubianos e aumento do pênis (PORTO CC, 2019). Nesse período, também surgem odor e pelos axilares, além de acne e aumento da oleosidade da pele (PAULA LCC e PUÑALES M, 2016).

A Escala de Tanner determina, através de uma descrição de 5 estágios, o nível de desenvolvimento mamário e dos pelos em meninas e o desenvolvimento da genitália e dos pelos nos meninos (MADEIRA IR e CORDEIRO MDM, 2019). Em ambos os sexos, os estágios dos pelos pubianos são classificados como: ausência de pelos (P1); pelos finos, longos e pouco pigmentados ao redor dos grandes lábios ou na base do pênis (P2); pelos escuros e um pouco mais grossos em pequena quantidade sobre o púbis (P3); pelos adultos na região púbica (P4) e pelos adultos na região púbica e no interior das coxas (P5) (BURNS DAR, et al., 2017).

De acordo com os critérios de estadiamento puberal de Tanner, o desenvolvimento das mamas no sexo feminino é descrito como: elevação das papilas, com ausência de tecido glandular (M1); broto mamário palpável sob a auréola (M2); mamas levemente aumentadas, sem desenvolvimento aureolar (M3); projeção da aureola, formando um "montículo" (M4); e hiperpigmentação aureolar, desenvolvimento de papilas e protusão dos mamilos, formando a mama adulta (M5) (EMMANUEL M e BOKOR BR, 2020).

De mesma maneira, no sexo masculino o desenvolvimento da genitália é classificado como: genitália infantil (G1); aumento do volume dos testículos, alteração da textura da pele do escroto e aumento peniano pequeno ou ausente (G2); aumento dos testículos, escroto e do comprimento do pênis (G3); aumento do diâmetro peniano, desenvolvimento da glande e aumento com enrugamento e pigmentação da pele dos testículos e escroto (G4); genitália adulta (G5) (BURNS DAR, et al., 2017).

Já o estirão de crescimento é determinado pelo aumento da estatura. Após o primeiro ano de vida, a puberdade é a fase em que a criança mais cresce. No sexo feminino, o estirão coincide com o estágio 2 de Tanner, enquanto no sexo masculino é mais tardio, acontecendo concomitantemente com o estágio 3. Nessa fase também há aumento de massa e força muscular, principalmente nos homens (PORTO CC, 2019).

Na PPC ou GnRH dependente, há ativação antecipada do eixo hipotálamo-hipófise-gônada. Esta é a forma mais comum de puberdade precoce, acometendo 1 a cada 5.000 a 10.000 crianças. No sexo feminino, ela é cerca de 10 vezes mais frequente e na grande maioria dos casos é idiopática. Já no sexo masculino, dois terços dos casos estão correlacionados com alterações neurológicas, sendo $50 \%$ destes causados por tumores do Sistema Nervoso Central (SNC) (MADEIRA IR e CORDEIRO MDM, 2019; LIMA LPV, et al., 2018).

A principal alteração clínica na PPC é o crescimento acelerado. Nos meninos há aumento bilateral e simétrico do volume testicular $(>2,5 \mathrm{~cm}$ ) com ou sem pubarca (aparecimento de pelos pubianos) ou axilarca (aparecimento de pelos axilares). Nas meninas, observa-se o surgimento da telarca (desenvolvimento das mamas) com ou sem o desenvolvimento de pubarca ou axilarca. Nos exames laboratoriais, os valores séricos basais e pós-estímulo do LH, FSH e esteróides sexuais estão em níveis puberais. Em exames de imagem, a idade óssea está avançada em relação à idade cronológica e há aumento bilateral e simétrico dos ovários (ALVES CAD, 2019). 
As mutações genéticas, apesar de estarem presentes na minoria dos casos, também podem estar associadas à PPC. Dentre tais variações, a mais frequente pode ser destacada em mutações inativadoras do gene MKRN3 (perda de função), fator negativo envolvido na repressão do início da puberdade, que ao ser inativado leva a diminuição do bloqueio e início precoce da puberdade. Este, localiza-se no cromossomo $15 q$ numa região de impriting relacionada à síndrome de Prader-Willi, na qual é a causa mais frequente de PPC familiar, sendo $46 \%$ dos casos familiares e $5 \%$ dos casos esporádicos (ALVES CAD, 2019).

Além desta, outras causas monogênicas incluem mutações no KISS1 e seu receptor KISS1R, potentes estimuladores da secreção do $\mathrm{GnRH}$, e que podem levar a um hipogonadismo hipogonadotrófico normósmico (PAZOLINI MCS, 2018). Localizado no cromossomo 1q32-q41, o gene KISS1 codifica a kisspeptina, que ao se ligar em seu receptor forma o complexo fundamental no início da puberdade (ALVES CAD, 2019). Por último, vale lembrar a mutação inativadora do gene associado, o DLK1, também conhecido por fator préadipócito 1 com papel na inibição da diferenciação de adipócitos expresso predominantemente nas adrenais, ovários e hipófise (VALADARES LP, 2019). O gene em questão fica localizado no cromossomo 14 em uma região de impriting relacionada à síndrome de Temple, descrita como causadora de PPC (ALVES CAD, 2019).

O Hamartoma Hipotalâmico é uma das causas orgânicas mais comuns de PPC nos dois sexos. São tumores não neoplásicos, que se manifestam como massas heterotópicas, com neurônios displásicos, que possuem como localização mais frequente a base do crânio, sendo que as formas pedunculadas desse tumor estão mais associadas ao desenvolvimento de puberdade precoce central. As manifestações clínicas são variáveis podendo apresentar crises gelásticas, distúrbios comportamentais e demência. Esta condição pode ser tratada com bloqueio da puberdade e retirada da lesão (MAIA TP, et.al., 2019)

A fisiopatologia relacionada à PPC não é bem esclarecida, mas acredita-se que seja pela produção do fator de crescimento transformante alfa (TGF-alfa) que estimula a liberação de $\mathrm{GnRH}$, ou por um distúrbio das vias de inibição do GnRH. Outra hipótese provável é a de que as vias que inibem o hipotálamo, neurohipófise e infundibulum sejam suspensas devido a compressão mecânica causada pelo tumor ou que esse tumor também tenha uma função neurossecretora (MAIA TP, et al., 2018; ALVES CAD, 2019).

A Neurofibromatose tipo 1, também conhecida como doença de Von Recklinghausen, trata-se de uma doença genética autossômica dominante com evolução progressiva, localizada no braço longo do cromossomo 17. Essa alteração é um gene de supressão tumoral que codifica proteínas citoplasmáticas neurofibrominais, sendo relacionada à PPC devido à alteração do gene NF-1 (ALVES CAD, 2019).

Para fazer o diagnóstico clínico, é necessário que tenha, pelo menos, dois dos seguintes achados: seis ou mais manchas "café com leite" com diâmetro superior a $5 \mathrm{~mm}$ em crianças pré-púberes ou 6 ou mais manchas "café com leite" com diâmetro maior que $15 \mathrm{~mm}$ em crianças pós-púberes, dois ou mais neurofibromas de qualquer tipo ou 1 neurofibroma plexiforme, dois ou mais nódulos de Lisch (hamartoma na íris),sardas axilares ou inguinais, glioma de nervo óptico, lesão óssea (displasia do esfenóide ou pseudartrose tibial), história familiar de primeiro grau (pais, irmãos ou filhos) com diagnóstico de NF-1 (REINEHR T e ROTH CL, 2018).

Além disso, tem-se como causa da PPC os astrocitomas pilocíticos, gliomas de baixo grau que podem ser encontrados no cerebelo, hipotálamo e no trato óptico. É mais comum entre os 6 e 9 anos, afetando mais o sexo masculino, podendo apresentar crescimento insidioso e raramente formar metástases. Possui manifestações clínicas como cefaléia e convulsões da puberdade precoce. Já os tumores da pineal propiciam a PPC devido à secreção de gonadotrofinas pelas células germinativas do tumor ou pela hidrocefalia causada pelo tumor que comprime o hipotálamo. Se manifesta como Síndrome de Parinaud, em que o paciente não consegue olhar para cima devido a compressão do tronco cerebral pelo tumor (ALVES CAD, 2019).

A PPP ou GnRH independente é gerada pela secreção de gonadotrofinas e esteróides sexuais de fontes endógenas ou exógenas. A PPP pode ser de origem adrenal (hiperplasia adrenal congênita ou tumores adrenais), ovariana (cistos ovarianos foliculares autônomos, tumores das células da granulosa, arrenoblastoma ou Síndrome de McCune-Albright), testicular (tumores produtores de hCG, tumores das 
células de Leydig, testotoxicose esporádica ou familiar), decorrente de consequências do hipotiroidismo primário, de outras causas genéticas ou até de etiologia idiopática (MADEIRA IR e CORDEIRO MDM, 2019).

Na PPC o crescimento também é acelerado. Nos meninos a palpação dos testículos mostra, em maioria, que estão de tamanho pré-púbere, podendo haver assimetria ou, mais raramente, aumento do volume em ambos os testículos. Nos exames laboratoriais, os valores séricos basais e pós-estímulo do LH e FSH estão em níveis pré-púberes, já os valores dos esteróides sexuais estão em níveis puberais. Nos exames de imagem, a idade óssea está avançada em relação à cronológica. Quando feita ultrassonografia pélvica em meninas, podem ser observados ovários de tamanho pré-púbere ou aumento de um deles (CHEN C, et al., 2017).

Em relação às principais causas da PPP, tem-se o Produtor de Gonadotrofina Coriônica Humana. Esse tumor pode ser oriundo de tumor misto de células germinativas, pinealoma, hepatoma, hepatoblastoma, teratoma e corioepitelioma, podendo ser associado também à síndrome de Klinefelter. Ele com puberdade precoce somente em meninos devido ao aumento dos níveis de HCG que ativam os receptores de LH nas células de Leydig do testículo, aumentando a produção de testosterona, pode ocorrer uma reação cruzada entre os hormônios LH e hCG fazendo com que ocorra falsas concentrações elevadas de LH (REINEHR T e ROTH CL, 2018).

As manifestações clínicas são aumento bilateral dos testículos, com desproporção entre o tamanho dos testículos e do pênis, além disso os pacientes apresentam pubarca precoce, crescimento peniano e virilização. Esses achados são essenciais para o diagnóstico clínico, além disso o diagnóstico é confirmado também pelo exame laboratorial, que apresenta aumento dos níveis plasmáticos dos hormônios hCG e testosterona, com concentração normal de DHEA-S e 17-OHP (HEO JS, et al., 2016).

O hipotireoidismo primário prolongado é a única causa de PPP que gera desaceleração do crescimento e atraso na idade óssea, devido ao aumento do hormônio TSH que atua sobre os receptores de FSH gerando efeitos gonadotróficos, podendo gerar cistos ovarianos, telarca e menarca precoce. Em meninas pode cursar com telarca precoce, galactorreia e/ou sangramento vaginal recorrente. Já os meninos cursam com macroorquidismo (aumento do volume testicular). Há a manifestação de poucos pelos pubianos em ambos os sexos (MADEIRA IR, 2016).

A hiperplasia adrenal congênita é uma doença autossômica recessiva, que possui como característica principal a deficiência de enzimas que participam da síntese de cortisol. Sua forma clássica é dividida em aumento da produção de andrógenos, que gera diminuição na produção de aldosterona, e virilizante simples que cursa com genitália ambígua (no sexo feminino), aumento do clitóris, pubarca precoce, crescimento acelarado e avanço na idade óssea. A forma não clássica se manifesta geralmente entre os 4 e 8 anos, se manifestando com pubarca precoce, amenorréia primária ou secundária, hirsutismo, acne e infertilidade. Já no sexo masculino durante a infância pode gerar pubarcar precoce e virilização, no jovem ou adulto se manifesta com pubarca aumento dos testiculos e infertilidade (REINEHR T e ROTH CL, 2018).

O tumor adrenal em crianças pode estar relacionado à mutação no gene TP53 e a síndrome de LiFraumeni, sendo mais comum nos primeiros 5 anos de vida, e dos 40 aos 50 anos, tendo prevalêncua no sexo feminino. Em crianças, esse tumor se manifesta com virilização associada ou não a síndrome de Cushing, hipercotisolismo e podendo aparecer tumores secretores de aldosterona. Podendo haver alterações laboratoriais como DHEA-S, androstenediona, testosterona, 17-OHP e hipocalemia. O diagnóstico é feito através de ressonância magnética ou tomografia computadorizada do abdome, caso seja confirmado a presença do tumor deve-se fazer tomografia e cintilografia óssea de tórax para fazer o estadiamento do tumor (ANTUNES LA, et al., 2016).

Os tumores testiculares são tumores raros na infância, por isso a classificação desse tumor na infância e em adultos é diferente. Podem ser originados das células germinativas (tumor do saco vitelínico, teratoma, tumor de células mistas e seminoma), do estroma gonadal (tumor misto do estroma gonadal, de células de Leydig, Sertoli e granulosas), do tecido de sustentação (fibroma, leimioma e hemangioma), de lesões (cisto epidermóide e nódulos hiperplásicos) e dos anexos (rabdomiossarcoma e fibrossarcoma), sendo a origem 
mais comum o saco vitelínico. Apresentam como achados clínicos o aumento do escroto com aparecimento de massa indolor, podendo ter hidrocele, aumento do testículo, dor abdominal e ginecomastia (OLIVEIRA SM, et al., 2020).

A testoxicose é uma doença autossômica dominante, causada por mutação do gene do receptor do hormônio LH que causa secreção de testosterona pelas células de Leydig devido a maturação gerada pela ativação do gene. Esse tumor ocorre apenas em meninos (ALVES CAD, 2019). Ao nascimento, se manifesta com aumento do pênis, a partir de 1 ano de idade se manifesta com virilização, aumento bilateral dos testículos. Além disso, apresenta alterações laboratoriais como aumento da concentração plasmática do hormônio testosterona, DHEA-S, LH, FSH e hCG. O tratamento nesses casos é feito com cetoconazol ou com a junção de antiandrogênico e inibidor de aromatase (MADEIRA IR, 2016).

A síndrome de McCune Albright, causada pela mutação na proteína G3, leva à síntese de muitos hormônios. De maneira geral, se apresenta com 3 manifestações clássicas: PPP, manchas café com leite e displasia óssea fibrosa poliostótica, que começam aparecer a partir dos dois anos de idade. Em meninas, pode cursar com sangramento vaginal e aparecimento de características sexuais femininas. Já os meninos podem apresentar macroorquidismo, e laboratorialmente, aumento da secreção de testosterona (ALVES CAD, 2019).

O tratamento de escolha para a puberdade precoce, cujo objetivo é o melhor desenvolvimento psicossocial, estatural e sexual, varia conforme a sua causa associada. Para a PPC, utiliza-se terapias com análogos de $\mathrm{GnRH}$ ( $\mathrm{GnRHa}$ ), que são responsáveis pela inibição dos receptores do $\mathrm{GnRH}$ na hipófise e, consequentemente, sua menor secreção. $O$ tratamento da PPP é realizado por meio de antagonistas de estrógenos ou andrógenos. A título de exemplificação, a abordagem terapêutica para a Síndrome de McCune Albright no sexo feminino é feita com inibidores de aromatase, por exemplo, letrozol e anastrozol, já no sexo masculino tem-se o uso de espironolactona. Em relação às causas tumorais de PPP, indica-se cirurgia para a remoção (AGUIRRE RS e EUGSTER EA, 2018; GUARALDI F, et al., 2016).

\section{CONSIDERAÇÕES FINAIS}

A partir dos dados supracitados, nota-se que a puberdade precoce é uma condição rara, que pode resultar, por exemplo, em transformações psicológicas e comportamentais, baixa estatura quando adulto, diabetes tipo 2 e maior risco de abuso sexual. Para a PPC, a qual depende do $\mathrm{GnRH}$, o tratamento é feito por análogos de $\mathrm{GnRH}$, já a PPP, que é independente do $\mathrm{GnRH}$, é tratada a partir antagonistas de estrógenos ou andrógenos e, em casos tumorais, recorre-se à remoção cirúrgica. Tanto a classificação da PP quanto seu tratamento têm como objetivo o melhor prognóstico, a fim de reduzir as consequências na vida da criança acometida.

\section{REFERÊNCIAS}

1. AGUIRRE RS, EUGSTER EA. Central precocious puberty: from genetics to treatment. Best Pract Res Clin Endocrinol Metab, 2018; 32(4): 343-354.

2. ALVES CAD. Endocrinologia Pediátrica. 1aㅡ ed. Manole, 2019; 49-53 p.

3. ANTUNES LA, et al. Adenocarcinoma de suprarrenal na infância. Relatos Casos Cir.2016;(3):1-4

4. BURNS DAR, et al. Tratado de Pediatria. 4를 ed. São Paulo: Editora Manole, 2017; 363-367p.

5. CARVALHO IV. Puberdade: endocrinologia e genética. Dissertação (Mestrado Integrado em Medicina) - Faculdade de Medicina da Universidade de Coimbra, Portugal, 2018.

6. CHEN C, et al. Investigating the relationship between precocious puberty and obesity: a cross-sectional study in Shanghai, China. BMJ Open, 2017; 7: 1-9.

7. GOMES RS, et al. Diagnóstico e Tratamento Da Puberdade Precoce. Revista Eletrônica Acervo Saúde, $2019 ; 24$.

8. GUARALDI F, et al. Resultados de longo prazo do tratamento da puberdade precoce central. European Journal of Endocrinology, 2016; 174: 79-87.

9. HEO JS, et al. Um estudo sobre hábitos alimentares e estilo de vida de meninas com puberdade precoce. PGHN, 2016; 2: 130-138.

10. LIMA LPV, et al. Avaliação clínica e laboratorial de meninas com diagnóstico de puberdade precoce central acompanhadas em ambulatório de referência. Rev Med UFC, 2019; 59 (1), 16-20.

11. MADEIRA IR. Puberdade Precoce. Revista HUPE, 2016; 15 (2):155-162 
12. MADEIRA IR, CORDEIRO MDM. Endocrinologia pediátrica. 2nd ed. Editora Manole, 2019; 41-47.

13. MAIA TP, et al. Puberdade Precoce Central Secundária à Hamartoma hipotalâmico: relato de caso. e-Scientia, 2019; 46-48.

14. MEDEIROS PCS, et al. Puberdade precoce e as consequências emocionais no desenvolvimento infantil. Revista Eletrônica Acervo Saúde, 2021; 13(4): e7127.

15. PAULA LCC, PUÑALES M. Puberdade Precoce. Sociedade Brasileira de Pediatria, 2016.

16. PAZOLINI MCS. Avanços no diagnóstico genético da puberdade precoce central. Dissertação (Doutorado em Endocrinologia). Faculdade de Medicina da Universidade de São Paulo, São Paulo, 2018, 35 p.

17. PORTO CC. Semiologia Médica. 8ª ed. Grupo GEN, 2019; 1269.

18. OLIVEIRA SM, et al. Correlação entre tumores de células de leydig e puberdade precoce: uma Revisão da Literatura. Revista Portuguesa de Endocrinologia, Diabetes e Metabolismo, 2020; 7(2): 62-141.

19. REINEHR T, ROTH CL. Is there a causal relationship between obesity and puberty? Lancet Child Adolesc Health, 2018; 13: 1-11.

20. VALADARES LP. Investigação de alterações genéticas em indivíduos com puberdade precoce central inicialmente classificada como idiopática. Tese (Doutorado em Ciências da Saúde) —Universidade de Brasília. Brasília, 2019. 